\title{
Isolation, culture and induced differentiation of rabbit mesenchymal stem cells into osteoblasts
}

\author{
HAO LIU ${ }^{1}$, LI-KUN WEI ${ }^{2}$, XIAO-FEI JIAN ${ }^{1}$, JIE HUANG ${ }^{1}$, HUI ZOU ${ }^{1}$, \\ SHI-ZHAN ZHANG ${ }^{1}$ and GUANG-HUA YUAN ${ }^{3}$
}

\begin{abstract}
Departments of ${ }^{1}$ Orthopedics and ${ }^{2}$ Stomatology, The Central Hospital of Wuhan, Tongji Medical College, Huazhong University of Science and Technology, Wuhan, Hubei 430014; ${ }^{3}$ Department of Orthopedics, Wuhan Xinzhou District People's Hospital, Wuhan, Hubei 430400, P.R. China
\end{abstract}

Received December 13, 2016; Accepted November 29, 2017

DOI: $10.3892 /$ etm.2018.5894

\begin{abstract}
Mesenchymal stem cells (MSCs) may be easily isolated from the bone marrow, and possess multi-lineage differentiation potential and various therapeutic applications. The differentiation of MSCs into osteoblasts is a complex process that is regulated by multiple internal and external factors. In the present study, the differentiation of MSCs isolated from rabbit bone marrow into osteoblasts using different osteoblast inductive media in the presence of dexamethasone, bone morphogenetic protein 2 (BMP-2), 1,25-dihydroxyvitamin D3, transforming growth factor $\beta$ (TGF $\beta$ ), platelet lysate and cyclooxygenase 2 (COX2), respectively. Alkaline phosphatase (ALP) activity, mineralization, collagen type $(\mathrm{Ct}) \mathrm{I}$ and osteocalcin activities, and the mRNA and protein expression levels of vascular endothelial growth factor (VEGF), BMP-2 and Ct II were measured during the differentiation process in MSCs treated with different inducers. Rabbit MSCs were successfully isolated and were observed to be predominantly circular in shape after culture for $24 \mathrm{~h}$. Following subculture for 5 days, the cells demonstrated a spindle shape. ALP, Ct I and osteocalcin activities were higher in cells cultured in dexamethasone, BMP-2 and TGF $\beta$ compared with the activities in control cells. Following differentiation, the dexamethasone, BMP-2 and TGF $\beta$ groups demonstrated significantly enhanced mineralization of MSCs detected by Alizarin Red S staining. The mRNA and protein expression levels of VEGF, BMP-2 and Ct II were significantly increased in the same groups compared with the levels in the control group. In conclusion, rabbit MSCs were successfully isolated from bone marrow and differentiated into osteoblasts
\end{abstract}

Correspondence to: Dr Hao Liu, Department of Orthopedics, The Central Hospital of Wuhan, Tongji Medical College, Huazhong University of Science and Technology, 26 ShengLi Road, Wuhan, Hubei 430014, P.R. China

E-mail: haoliu6027@sina.com

Key words: mesenchymal stem cells, osteoblasts, differentiation, dexamethasone, bone morphogenetic 2 , transforming growth factor $\beta$ indicated by raised ALP, Ct I and osteocalcin activities, mineralization and expression of osteogenesis-inducing genes and proteins. The present study revealed that dexamethasone, BMP-2 and TGF $\beta$ have a positive effect on cell differentiation.

\section{Introduction}

Marrow mesenchymal stem cells (MSCs) derived from the bone marrow stromal system have different and distinct lineage potential (1). Bone marrow MSCs may be easily isolated and exhibit a multipotent nature, including the ability to be greatly expanded in vitro and induced to differentiate into multiple mesenchymal cell types (2). MSCs serve as precursors for various mesoderm-type cells, including osteoblasts, chondroblasts and adipocytes (3-5). As MSCs are easily obtained and have strong osteogenic differentiation capabilities, they are widely applied in cellular therapy, tissue repair and regenerative medicine $(6,7)$

Differentiation of MSCs into osteoblasts is a complex process that is regulated by the expression of various transcription factors, predominantly vascular endothelial growth factor (VEGF) and bone morphogenetic protein 2 (BMP-2), and expression of osteoblast-specific proteins, including alkaline phosphatase (ALP) and collagen type (Ct) II (8-10). Dexamethasone and other factors, including transforming growth factor $\beta$ (TGF $\beta)$, cyclooxygenase 2 (COX2) and platelet lysate, as pluralistic osteogenic inducers have attracted widespread attention from researchers (11). Ahmad and Shakoori (12) have illustrated that dexamethasone treatment accelerated murine MSC proliferation and induced early differentiation of osteoblasts. BMP-2 is the most widely studied and is the most potent inducer of osteoblastic differentiation $(13,14)$. It has previously been reported that BMP-2 enhanced TGF 33 -mediated chondrogenesis of human bone marrow MSCs, which suggested that the combination of BMP-2 and TGF $\beta 3$ is superior to promote MSC osteogenic differentiation using TGF- $\beta$ alone in MSCs chondrogenesis (15).

Multiple studies have demonstrated that environmental and hormonal factors as well as factors secreted by the cells themselves, serve an important role in the differentiation of MSCs into osteoblasts $(16,17)$. Various approaches and methodologies have been utilized to study the molecular mechanism of 
MSC differentiation into osteoblasts (18-20). In the present study, MSCs were isolated from bone marrow of rabbits and the differentiation process of osteoblasts was studied using various cell culture media. Prior to differentiation, the first, second and third passages of cells were performed to observe cell morphology alterations, and the positive rate of MSC antigen presentation of cluster of differentiation CD44 and CD105 was measured for cell identification. Following various cultures, the activity of ALP by Alizarin Red S staining was determined, and $\mathrm{Ct} \mathrm{I}$ and osteocalcin activities were measured using immunohistochemical staining. Reverse transcription-quantitative polymerase chain reaction (RT-qPCR) and western blotting were used to evaluate the expression of VEGF, BMP-2 and Ct II.

\section{Materials and methods}

Experimental animals. One male New Zealand white rabbit (age, 4 months; weight, 2.5-3.0 kg) was obtained from Hubei Provincial Center for Disease Control and Prevention (Wuhan, China). The rabbit was housed in a cage at $25 \pm 3^{\circ} \mathrm{C}$ in a $12 \mathrm{~h}$ light/dark cycle with $50 \%$ relative humidity and received dry pellets ad libitum with the intermittent addition of green fodder. All animal experiments were performed according to the Policies on the Use of Animals and Humans in Neuroscience Research, revised and approved by the Society for Neuroscience in 1995 (21). All protocols involving animal specimens were approved by the Ethical Committee of Tongji Hospital, Tongji Medical College, Huazhong University of Science and Technology Institution (Wuhan, China).

Isolation and culture of rabbit MSCs. A total of 10-15 ml femoral supracondylar bone marrow of New Zealand rabbits was extracted by bone marrow cavity puncture as previously described (12). MSCs were flushed out using Dulbecco's modified Eagle's medium (DMEM; incomplete) (Gibco; Thermo Fisher Scientific, Inc., Waltham, MA, USA). A single cell suspension was obtained by passing the flushed-out cells through a 22-gauge needle several times and counting the number of cells using a hemocytometer. DMEM supplemented with $10 \%$ fetal bovine serum (Invitrogen; Thermo Fisher Scientific, Inc.), glutamine $10 \mathrm{mmol} / \mathrm{l}, 100 \mathrm{U} / \mathrm{ml}$ penicillin and $100 \mu \mathrm{g} / \mathrm{ml}$ streptomycin was added to the cell suspension in 12 -well culture plates. The plates were incubated at $37^{\circ} \mathrm{C}$ with $95 \%$ air and $5 \% \mathrm{CO}_{2}$. After $96 \mathrm{~h}$ of incubation, the cells were washed with PBS and transferred to 96-well culture plates and cultured at $37^{\circ} \mathrm{C}$ with $95 \%$ air and $5 \% \mathrm{CO}_{2}$. When cells reached $80 \%$ confluence, the attached cells were trypsinized with $0.125 \%$ trypsin for subculture.

Flow cytometric identification. Cells at the fourth passage were digested using $0.125 \%$ trypsin and centrifuged at $500 \mathrm{xg}$ for $10 \mathrm{~min}$ at room temperature. Following centrifugation, the cells were washed with PBS three times, and the cell concentration was adjusted to $1 \times 10^{6}$ cells $/ \mathrm{ml}$. The cells were incubated in $3 \%$ bovine serum albumin (BSA; Sigma-Aldrich; Merck KGaA, Darmstadt, Germany) for $20 \mathrm{~min}$ at $4^{\circ} \mathrm{C}$ to block non-specific protein. Fluorescence-labeled anti-CD44 (ab157107; 1:100 dilution) and anti-CD105 (ab135528; 1:50 dilution) (both Abcam, Cambridge, UK) antibodies were added to each tube and incubated for $20 \mathrm{~min}$ in darkness at $4^{\circ} \mathrm{C}$. The unbound antibodies were washed off using PBS. The cells were subsequently incubated with fluorescein isothiocyanate conjugated goat-anti-rabbit immunoglobulin (Ig) G secondary antibodies (ab97050; 1:200; Abcam) for $40 \mathrm{~min}$ at room temperature. Cell surface antigens were detected using a flow cytometer (Cytomics FC 500; Beckman Coulter, Inc., Brea, CA, USA) and the results analyzed by CXP 2.1 software (Beckman Coulter, Inc.).

Differentiation of induced, cultured MSCs into osteoblasts. For osteoblast induction, second passage MSCs (inoculation concentration, $1 \times 10^{6}$ cells $/ \mathrm{ml}$ ) were cultured in each well of 24-well plates and divided into six experimental groups $(n=3)$ and a control group $(n=3)$. The six experimental groups were created by the addition of one of the following to the complete culture medium: Dexamethasone $1 \times 10^{-8} \mathrm{~mol} / \mathrm{l}$ dexamethasone (D4902) $+10 \mathrm{mmol} / \mathrm{l}$ sodium $\beta$-glycerophosphate (G9422) + $50 \mu \mathrm{g} / 1$ vitamin C (A4544); BMP-2 (B1814); COX2 (C0858); platelet lysate (SCM141); 1,25-dihydroxyvitamin D3[1,25-(OH) 2 VD3] (H107) (all Sigma-Aldrich; Merck KGaA); and TGF $\beta$ (14-8348-62; Thermo Fisher Scientific, Inc.). The cells of the control group were cultured in complete medium. Cells were incubated at $37^{\circ} \mathrm{C}$ with $95 \%$ air and $5 \% \mathrm{CO}_{2}$ and the culture medium in each group was changed every 3 days.

ALP activity. ALP activity staining was measured in all experimental groups and the control group after 7 days of culture. For this purpose, MSC layers were washed twice with PBS, fixed with $4 \%$ paraformaldehyde for $10 \mathrm{~min}$ at $4^{\circ} \mathrm{C}$, then, rinsed with PBS and stained with nitro blue tetrazolium and 5-bromo-4-chloro-3-indolyl phosphate for $2 \mathrm{~h}$ in darkness at room temperature. The chromogenic reaction was stopped by washing twice with $\mathrm{dH}_{2} \mathrm{O}$ and following drying the samples were observed using a light microscope at magnification, $\mathrm{x} 100$.

Alizarin Red S staining. Alizarin Red S staining was performed after growing the cells for 21 days in induction media. MSCs were washed twice with PBS and fixed with ice-cold $70 \%$ ethanol for $1 \mathrm{~h}$ at $4{ }^{\circ} \mathrm{C}$, and then rinsed with $\mathrm{dH}_{2} \mathrm{O}$ twice. Alizarin Red S solution was added to cover the cells and incubated at room temperature for $30 \mathrm{~min}$. The wells were washed four times with $\mathrm{dH}_{2} \mathrm{O}$ and images were taken using an inverted microscope at magnification, $\mathrm{x} 100$.

Immunohistochemical staining. The cell pellet was fixed in $4 \%$ paraformaldehyde for $20 \mathrm{~min}$ at $4^{\circ} \mathrm{C}$ and washed twice with PBS. Cells were incubated in $0.5 \%$ Txiton X-100 for $20 \mathrm{~min}$ at room temperature, washed twice with PBS, and then treated with $3 \% \mathrm{H}_{2} \mathrm{O}_{2}$ for 15 min for the quenching of endogenous peroxidase activity at room temperature. The sections were washed twice using PBS for 2 min and antigen retrieval was performed with $2 \mathrm{mg} / \mathrm{ml}$ protease at $37^{\circ} \mathrm{C}$ for $30 \mathrm{~min}$. Sections were washed with PBS for $5 \mathrm{~min}$ and non-specific staining was blocked with 5\% goat serum (Sigma-Aldrich; Merck KGaA; 1:20 dilution with PBS containing 1\% BSA) for $20 \mathrm{~min}$ at room temperature, followed by incubation with specific antibody to $\mathrm{Ct} \mathrm{I}$ and osteocalcin. Following cell cultured induction for 7 days, Ct I was detected. Sections were incubated with a mouse monoclonal antibodies against Ct I (ab21286; 1:200 
Table I. Primers used for reverse transcription-quantitative polymerase chain reaction.

Direction $\left(5^{\prime}-3^{\prime}\right)$

\begin{tabular}{lll}
\cline { 2 - 2 } Gene & \multicolumn{1}{c}{ Forward } & \multicolumn{1}{c}{ Reverse } \\
\hline Bone morphogenetic protein 2 & GTGAGGATTAGCAGGTCTT & CTGGATTTGAGGCGTTT \\
Vascular endothelial growth factor & GACATCTTCCAGGAGTACCC & GAGGTTTGATCCGCATGAT \\
Collagen type II & AACACTGCCAACGTCCAGAT & AGTGGATATGGCACGACGTC \\
GAPDH & ACCCACTCCTCTACCTTCG & CACCACCCTGTTGCTGT
\end{tabular}
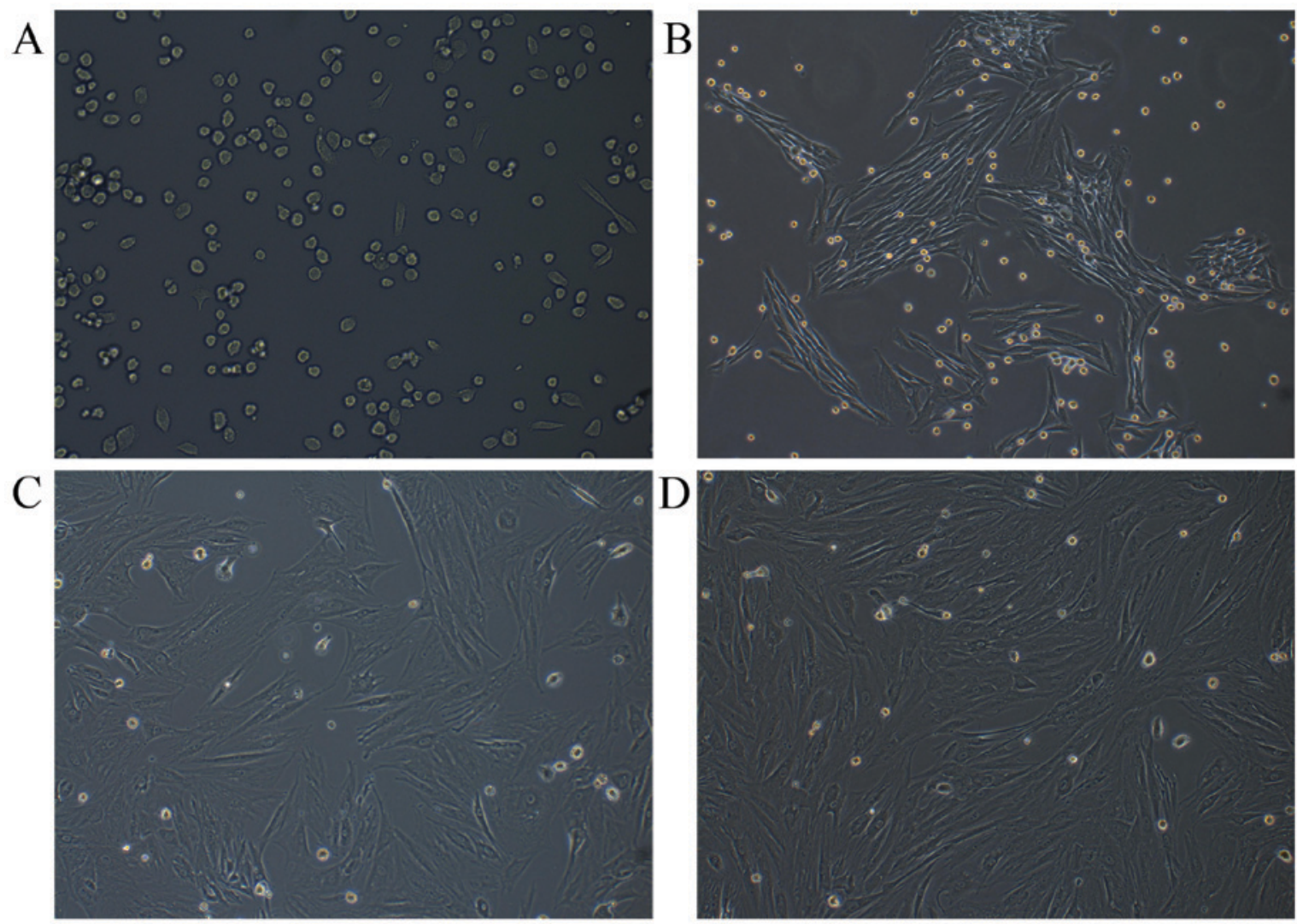

Figure 1. Morphology of rabbit MSCs. (A) Primary MSCs were cultured for 1 day and circular-shaped cells of uniform size. (B) MSCs at the first passage were cultured for 5 days. (C) MSCs at the second passage were cultured for 5 days. (D) MSCs at the third passage were cultured for 5 days. MSCs were spindle-shaped (fibroblast-like cells) in first, second and third passages after cultured for 5 days. MSCs, mesenchymal stem cells. Magnification, x100.

dilution; Abcam) overnight at $4^{\circ} \mathrm{C}$. The spatial localization of $\mathrm{Ct}$ I was visualized by incubation with mouse $\mathrm{IgG}$ horseradish peroxidase (HRP)-conjugated secondary antibodies (ab6728; 1:200 dilution; Abcam) for $1 \mathrm{~h}$ at room temperature, followed by 3,3'-diaminobenzidine tetrahydrochloride (Sigma-Aldrich; Merck KGaA) in the presence of $\mathrm{H}_{2} \mathrm{O}_{2}$ for 5-10 min at room temperature.

Following induction for 14 days, osteocalcin was detected. Sections were incubated with a mouse monoclonal antibody to osteocalcin $\left(1: 200\right.$; Abcam) overnight at $4^{\circ} \mathrm{C}$. The spatial localization of osteocalcin was visualized by incubation with goat IgG HRP-conjugated secondary antibody (ab6728; 1:200 dilution; Abcam) for $1 \mathrm{~h}$ at room temperature, followed by 3,3'-diaminobenzidine tetrahydrochloride (Sigma, Missouri, USA) in the presence of $\mathrm{H}_{2} \mathrm{O}_{2}$ for 5-10 min at room temperature.
Following this, the sections were rinsed with PBS, counterstained with hematoxylin for $3 \mathrm{~min}$ at room temperature, dehydrated with graded ethanol (80\% alcohol $1 \mathrm{~min}, 95 \%$ alcohol $1 \mathrm{~min}$ twice and dehydrated alcohol $1 \mathrm{~min})$ and xylene for 1 min twice, and mounted with Entellan ${ }^{\circledR}(\mathrm{KGaA})$. The sections were observed by light microscopy (CX41; Olympus Corporation, Tokyo, Japan) at magnification, x200.

$R N A$ extraction and $R T-q P C R$. Total RNA was extracted from cells in each group with TRIzol reagent (Takara Biotechnology Co., Ltd., Dalian, China) and detected by an ultraviolet spectrophotometer and 1\% agarose electrophoresis and visualized with ethidium bromide. For each sample, $1 \mu \mathrm{g}$ RNA was reverse transcribed to obtain first-strand cDNA using a PrimeScript ${ }^{\circledR}$ RT reagent kit with gDNA Eraser (Takara Biotechnology Co., Ltd.) according to the manufacturer's protocol at $42^{\circ} \mathrm{C}$ for $2 \mathrm{~min}$, 
A

(F1) [A]CD44.LMD:FLILOG

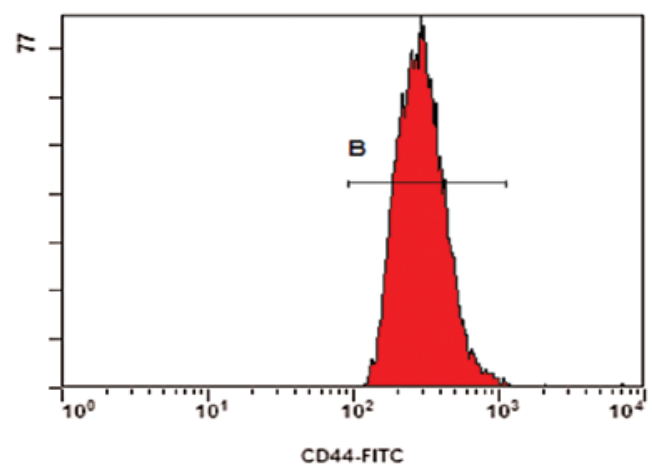

CD44.LMD : FL1 LOG

$\begin{array}{lccc}\text { Region } & \text { Number } & \text { \% Total } & \text { \% Gated } \\ \text { ALL } & 8092 & 80.92 & 100.00 \\ \text { B } & 7855 & 78.55 & 97.07\end{array}$

B

(F2) [A]CD105.LMD:FL1LOG

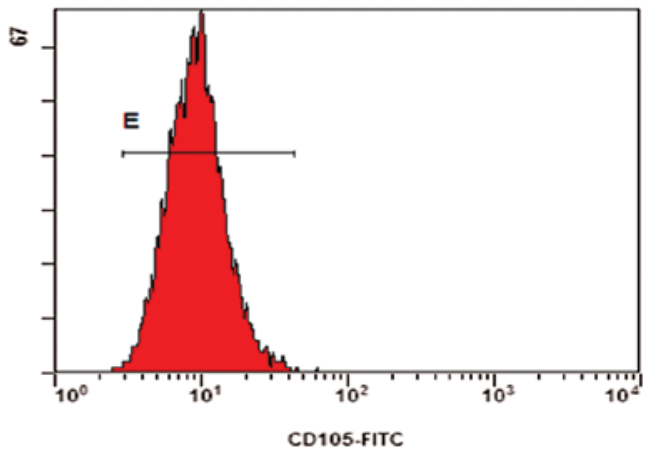

CD105.LMD : FL1 LOG

Region Number \% Total \% Gated

$\begin{array}{llll}\text { ALL } & 7998 & 79.98 & 100.00\end{array}$

$\begin{array}{llll}\text { E } & 7721 & 77.21 & 96.54\end{array}$

Figure 2.CD44- and CD105-positive rate of rabbit mesenchymal stem cells. The rate of positive staining for (A) CD44 and (B) CD105. CD, cluster of differentiation; $\mathrm{B}$ and $\mathrm{E}$ are the names of the gates used for flow cytometry analysis.

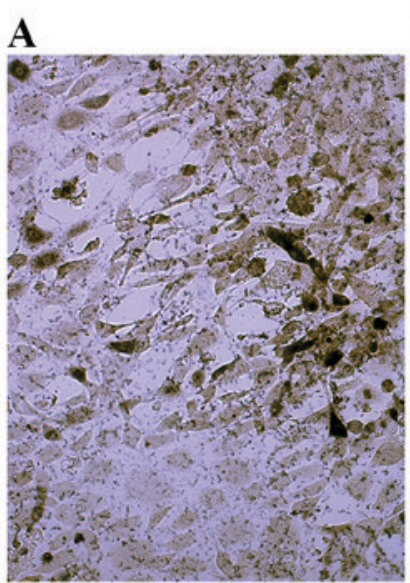

$\mathbf{E}$

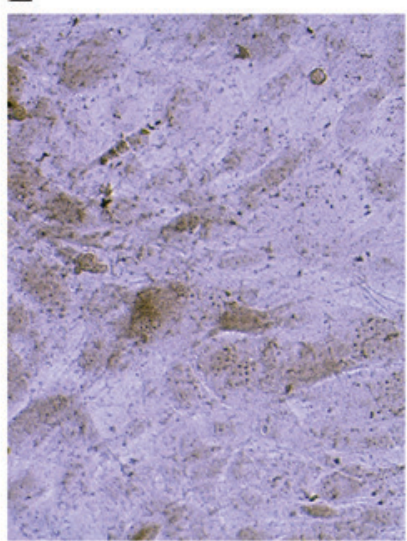

B

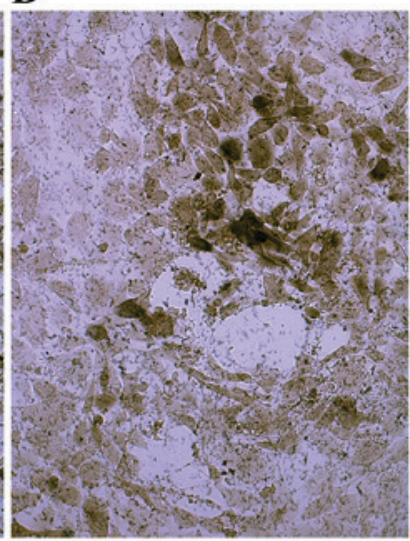

F
C

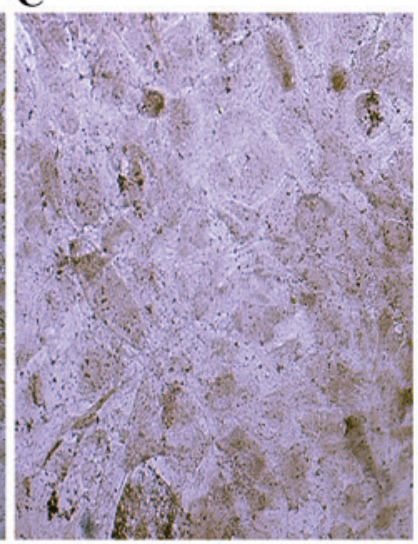

G

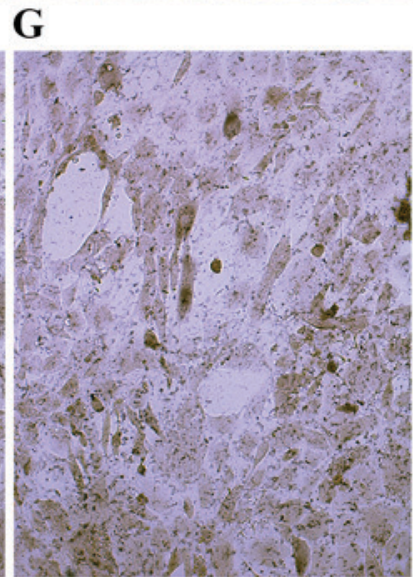

Figure 3. Phosphatase staining of control cells and cells cultured in osteogenic induction media. Cells cultured in (A) dexamethasone, (B) bone morphogenetic protein 2, (C) 1,25-dihydroxyvitamin D3, (D) transforming growth factor $\beta$, (E) platelet lysate, (F) cyclooxygenase 2 and (G) control media. Magnification, x200.

$37^{\circ} \mathrm{C}$ for $15 \mathrm{~min}$ and $85^{\circ} \mathrm{C}$ for $15 \mathrm{sec}$. Expression levels of target genes BMP2, VEGF and Ct II were analyzed using RT-qPCR. Primer Premier 5.0 (PREMIER Biosoft International, Palo Alto, CA, USA) was used to design the fluorescent primers (Table I).
Each reaction (20 $\mu \mathrm{l}$ total volume) contained $10 \mu \mathrm{l} 2 \mathrm{X}$ SYBR Premix Ex Taq ${ }^{\mathrm{TM}}$ (Takara Biotechnology Co., Ltd.), $0.50 \mu \mathrm{mol} / 1$ each primer and $0.2 \pm 0.02 \mu \mathrm{g}$ cDNA template. The following three-step RT-qPCR reaction was performed: Pre-denaturation 


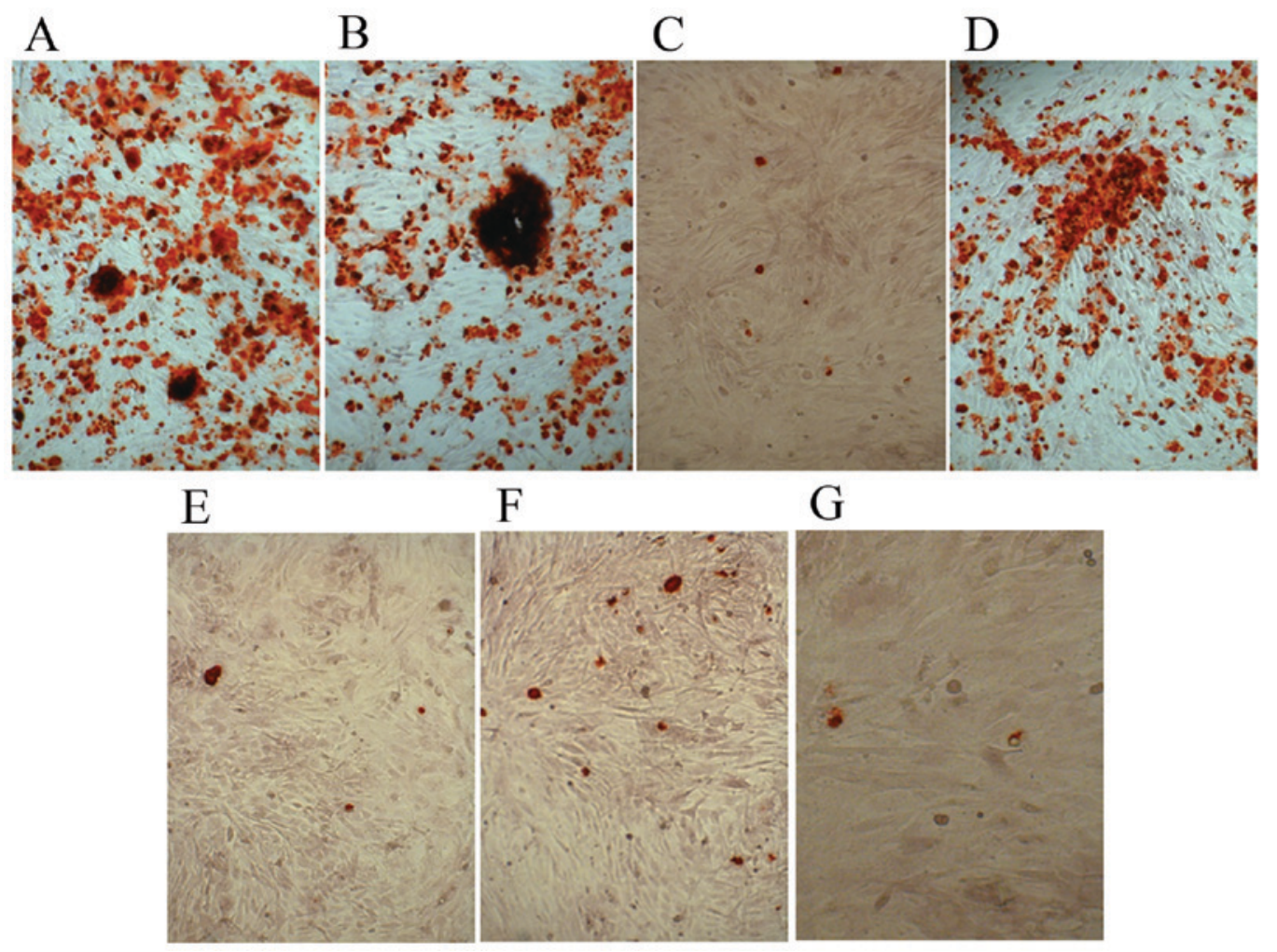

Figure 4. Alizarin Red S staining of control cells and cells cultured in osteogenic induction media. Cells cultured in (A) dexamethasone, (B) bone morphogenetic protein 2, (C) 1,25-dihydroxyvitamin D3, (D) transforming growth factor $\beta$, (E) platelet lysate, (F) cyclooxygenase 2 and (G) control media. Magnification, x100.
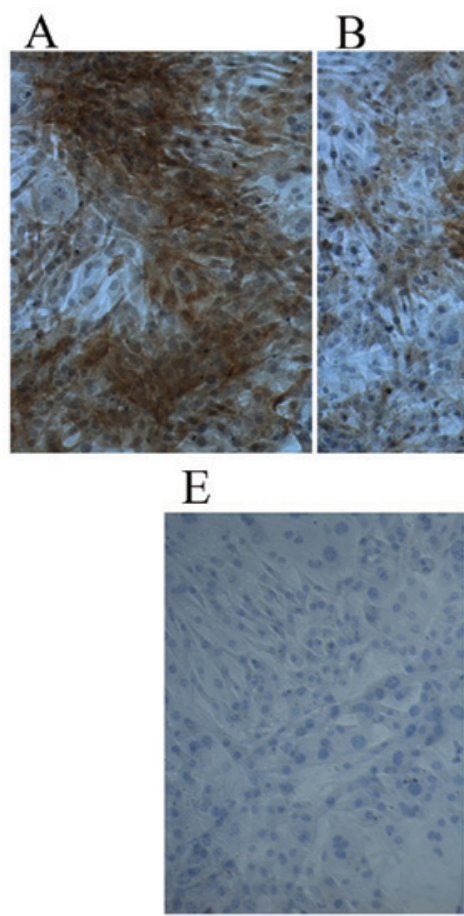

$\mathrm{C}$

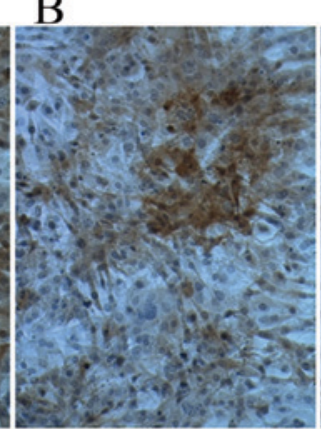

F
$\mathrm{D}$

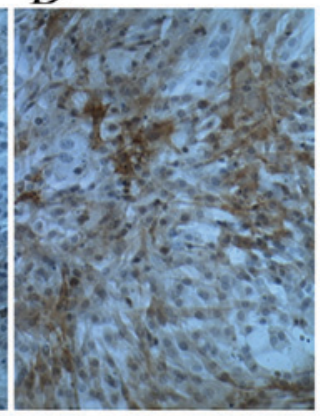

G

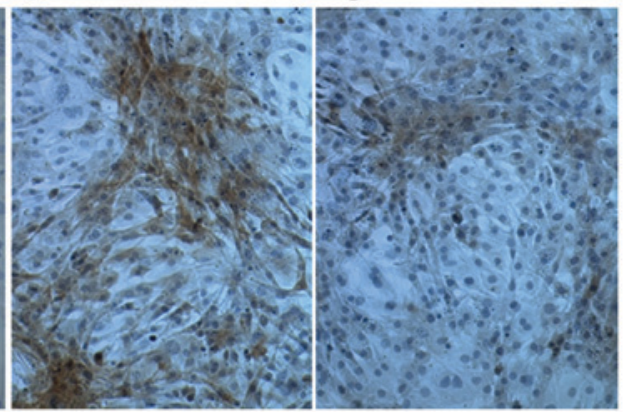

Figure 5. Immunohistochemical staining of collagen typeI in control cells and cells cultured in osteogenic induction media. Cells cultured in (A) dexamethasone, (B) bone morphogenetic protein 2, (C) 1,25-dihydroxyvitamin D3, (D) transforming growth factor $\beta$, (E) platelet lysate, (F) cyclooxygenase 2 and (G) control media. Magnification, x200.

at $95^{\circ} \mathrm{C}$ for $30 \mathrm{sec}$, followed by 40 cycles of denaturation at $95^{\circ} \mathrm{C}$ for $5 \mathrm{sec}$, annealing at $60^{\circ} \mathrm{C}$ for $20 \mathrm{sec}$ and elongation at $72^{\circ} \mathrm{C}$ for $20 \mathrm{sec}$. The transcriptional levels of genes were calculated using the $2^{-\Delta \Delta \mathrm{Cq}}$ method (22). By genome analysis, the results demonstrated that GAPDH was the most stable gene among the three commonly used housekeeping genes GAPDH, 18s ribosomal RNA and $\beta$-actin in all cells. The threshold cycle $(\mathrm{Ct})$ was determined for each reaction by using the $2^{-\Delta \Delta \mathrm{Cq}}$ method, 

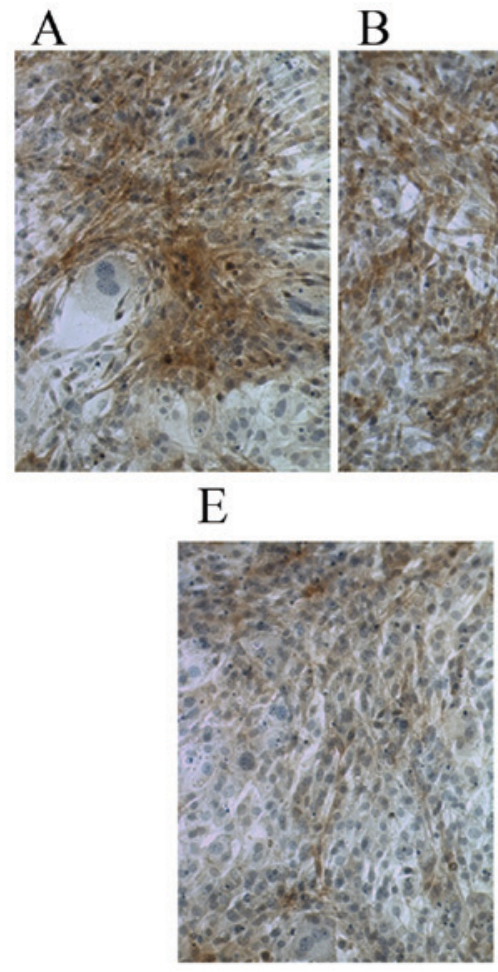

$\mathrm{C}$

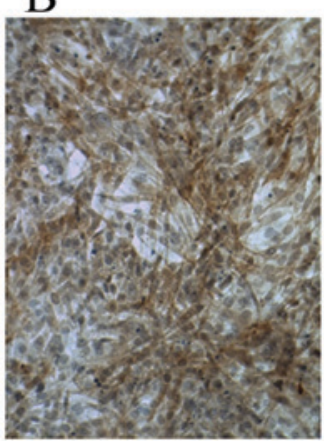

$\mathrm{F}$

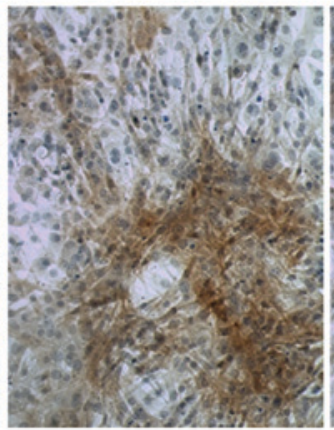

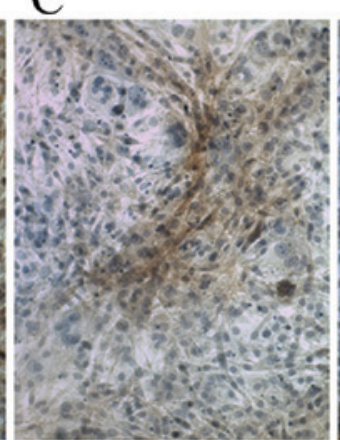

D

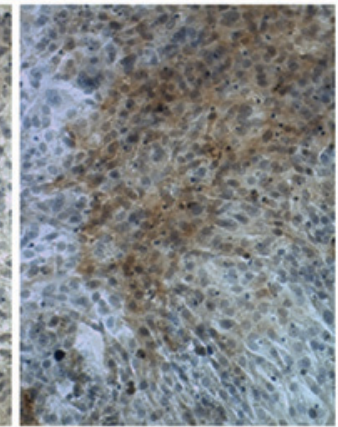

G

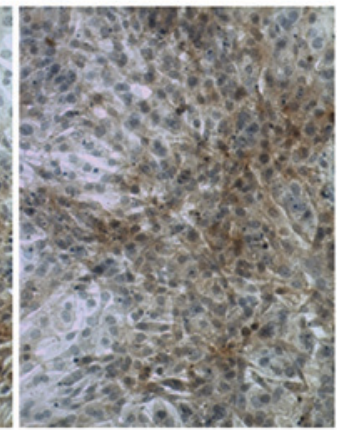

Figure 6. Immunohistochemical staining of osteocalcin in control cells and cells cultured in osteogenic induction media. Cells cultured in (A) dexamethasone, (B) bone morphogenetic protein 2, (C) 1,25-dihydroxyvitamin D3, (D) transforming growth factor $\beta$, (E) platelet lysate, (F) cyclooxygenase 2 and (G) control media. Magnification, x200.

which generated $\mathrm{Ct}$ values for each gene of interest normalized to the endogenous control gene (GAPDH). The quantification of target and reference genes was evaluated using standard curves, and the ratio between the target and reference gene represented the relative expression levels of the target gene. For each group, three samples were measured, and three technical replicates of each measurement were obtained.

Western blot analysis. Western blot analysis was performed to determine the expression of VEGF, BMP-2 and Ct II proteins in MSCs cultured in different cell culture media. The cells were homogenized with RIPA lysis buffer (Beijing Solarbio Science \& Technology Co., Ltd., Beijing, China) and centrifuged at $12,000 \mathrm{xg}$ for $20 \mathrm{~min}$ at $4^{\circ} \mathrm{C}$. The protein concentration was determined using a bicinchoninic acid protein assay kit (Bio-swamp; Wuhan Beinglay Biological Technology Co., Ltd., Wuhan, China). Equal amounts of protein $(30 \mu \mathrm{g})$ were separated by $10 \%$ SDS-PAGE and subsequently transferred to a polyvinylidene difluoride membrane (EMD Millipore, Billerica, MA, USA). The membranes were blocked for $2 \mathrm{~h}$ at room temperature with $5 \%$ skim milk in Tris-buffered saline $(20 \mathrm{mmol} / \mathrm{l}$ Tris, $500 \mathrm{mmol} / \mathrm{l} \mathrm{NaCl}$ and $0.05 \%$ Tween 20). Subsequently, the membrane was incubated with specific antibodies overnight at $4^{\circ} \mathrm{C}$, including rabbit anti-BMP-2 antibody (ab14933; 1:1,000; Abcam), rabbit anti-VEGF antibody (ab32152; 1:4,000; Abcam) and human anti-Ct II antibody (ab159157; 1:2,000; Abcam). Anti-GAPDH antibody (ab181602; 1:10,000; Abcam) was selected as an internal reference. Following this, the membranes were washed with Tris-buffered saline and incubated with goat anti-rabbit secondary antibody (PAB160009; 1:10,000; Bio-swamp;
Wuhan Beinglay Biological Technology Co., Ltd.) for $2 \mathrm{~h}$ at room temperature. Immunoreactivity was visualized by colorimetric reaction using an enhanced chemiluminescence substrate buffer (EMD Millipore). Membranes were scanned with a Gel Doz EZ imager and the bands were quantified using Quantity One 5.0 software (Bio-Rad Laboratories, Inc., Hercules, CA, USA).

Statistical analysis. All data were expressed as the mean \pm standard deviation. Statistical differences were analyzed by one-way analysis of variance using SPSS 18.0 (SPSS, Inc., Chicago, IL, USA). Significant differences were detected by the Duncan's test. $\mathrm{P}<0.05$ was considered to indicate a statistically significant difference.

\section{Results}

Observation and identification of rabbit MSCs. Rabbit MSCs were successfully isolated following the incubation of flushed-out cells from bone marrow. The MSCs were attached to the surface of the plate and were predominantly circular-shaped cells of uniform size after culture for $24 \mathrm{~h}$ (Fig. 1A). At the first, second and third passages, after 5 days, the cells were spindle-shaped (fibroblast-like cells), which is typical morphology of MSCs (Fig. 1B-D).

Detection of rabbit MSC surface antigens. Flow cytometric results demonstrated that the CD44- and CD105-positive rates of MSCs at the fourth passage were 97.07 and $96.54 \%$, respectively (Fig. 2A and B). The results revealed that the purity of the isolated and cultured MSCs in the experiment was high, 

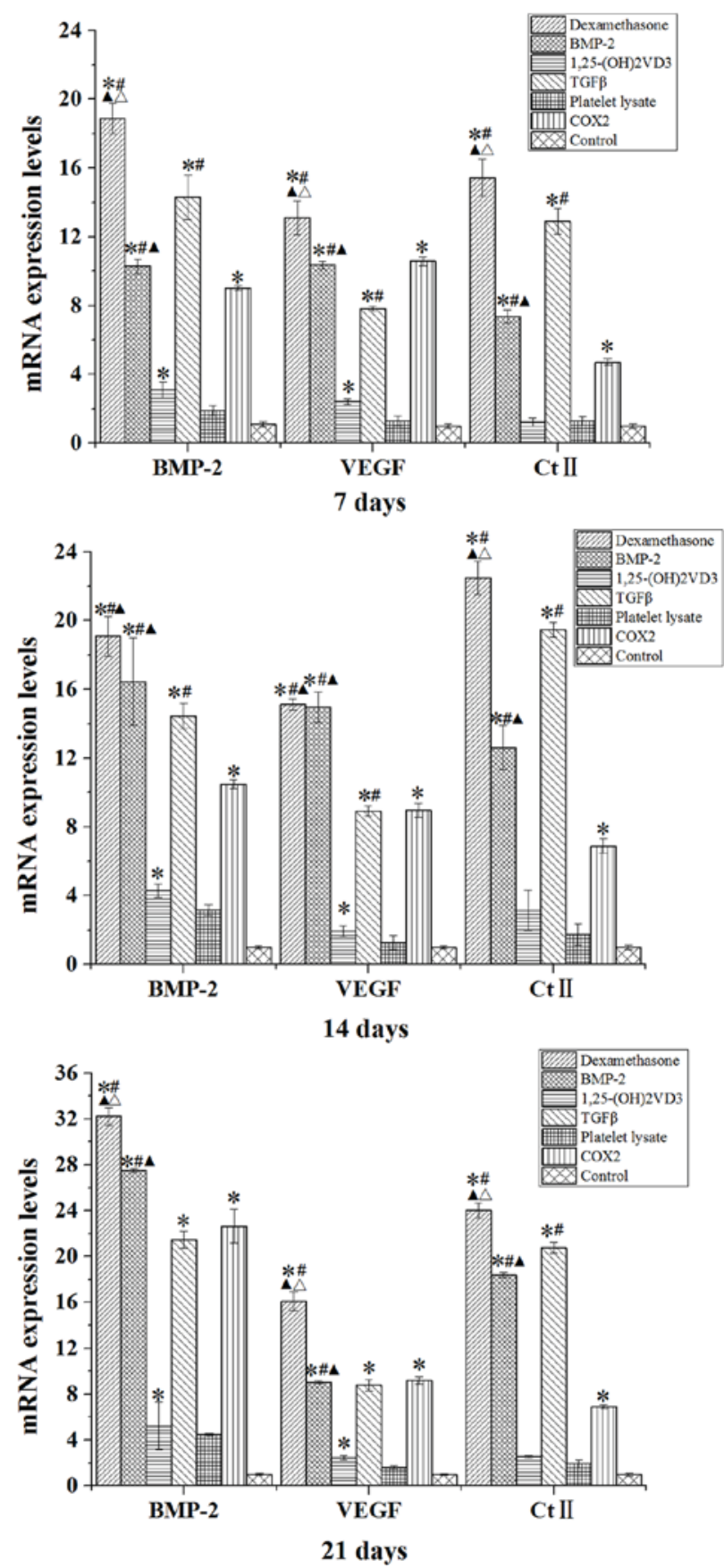

Figure 7. mRNA expression levels of BMP-2, VEGF and Ct II in rabbit mesenchymal stem cells cultured in osteogenic media for 7,14 and 21 days. Data are presented as the mean \pm standard deviation $(\mathrm{n}=3)$. ${ }^{*} \mathrm{P}<0.05$ vs. the control; ${ }^{\#} \mathrm{P}<0.05$ vs. the COX2 group; ${ }^{\wedge} \mathrm{P}<0.05$ vs. TGF $\beta$ group; ${ }^{\Delta} \mathrm{P}<0.05$ vs. BMP-2 group. BMP-2, bone morphogenetic protein 2; VEGF, vascular endothelial growth factor; $\mathrm{Ct}$ II, collagen type II; $1,25-(\mathrm{OH})_{2} \mathrm{VD} 3$, 1,25-dihydroxyvitamin D3; COX2, cyclooxygenase 2 .

confirming that the cells were derived from differentiated BMSCs following induction.

ALP staining. Following culture in osteogenic medium for 7 days, ALP staining was positive. Cells demonstrated gray-black and black granule precipitate in the cytoplasm precipitation (Fig. 3). Compared with the control group, ALP activity was markedly increased in the dexamethasone group, BMP-2 group and TGF 3 group (Fig. 3A, B and D). The

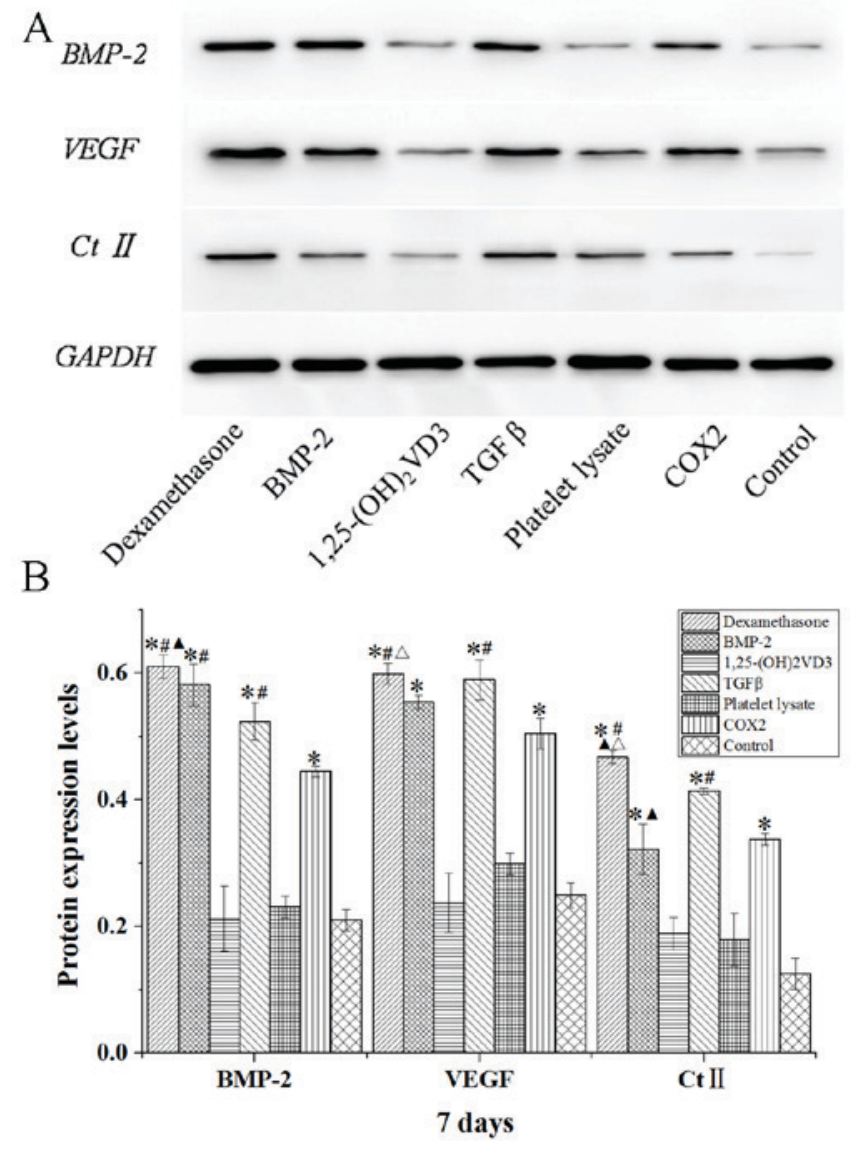

Figure 8. Western blot analysis of BMP-2, VEGF and Ct II protein expression levels in rabbit mesenchymal stem cells cultured in osteogenic media for 7 days. (A) Western blotting bands were quantified using Quantity One 5.0 and demonstrated as (B) BMP-2/GAPDH, VEGF/GAPDH and Ct II/GAPDH Data are presented as the mean \pm standard deviation $(n=3)$. ${ }^{*} \mathrm{P}<0.05$ vs. the control; ${ }^{\#} \mathrm{P}<0.05$ vs. the COX 2 group; ${ }^{\Delta} \mathrm{P}<0.05$ vs. TGF $\beta$ group; ${ }^{\Delta} \mathrm{P}<0.05$ vs. BMP-2 group. BMP-2, bone morphogenetic protein 2; VEGF, vascular endothelial growth factor; Ct II, collagen type II; 1,25-(OH) 2 VD3, 1,25-dihydroxyvitamin D3; COX2, cyclooxygenase 2 .

ALP activity in the COX2 group was higher than that in the $1,25-(\mathrm{OH})_{2} \mathrm{VD} 3$ group and platelet lysate group, but the COX-2 group was similar to the control group (Fig. 3E). These results indicated that treated with dexamethasone, BMP-2 or TGF $\beta$ notably increased ALP activity.

Alizarin Red S staining. The control cells and experimental groups with various osteoblast induction media were stained with Alizarin Red S following 21 days of differentiation. Alizarin Red S staining indicated dark red precipitated calcium deposits (Fig. 4). The dexamethasone, BMP-2 and TGF $\beta$ groups demonstrated markedly enhanced mineralization of MSCs compared with that observed in the other groups (Fig. 4A, B and D). Whereas cells in 1,25-(OH)2VD3, platelet lysate, COX-2 and control media were negative. The results demonstrated that dexamethasone, BMP-2 and TGF $\beta$ promoted mineralization of MSCs.

Ct I and osteocalcin are increased in MSCs following culture in osteogenic induction media. Following culture in osteogenic medium for 7 days, compared with the control group, Ct I and osteocalcin levels were markedly increased 


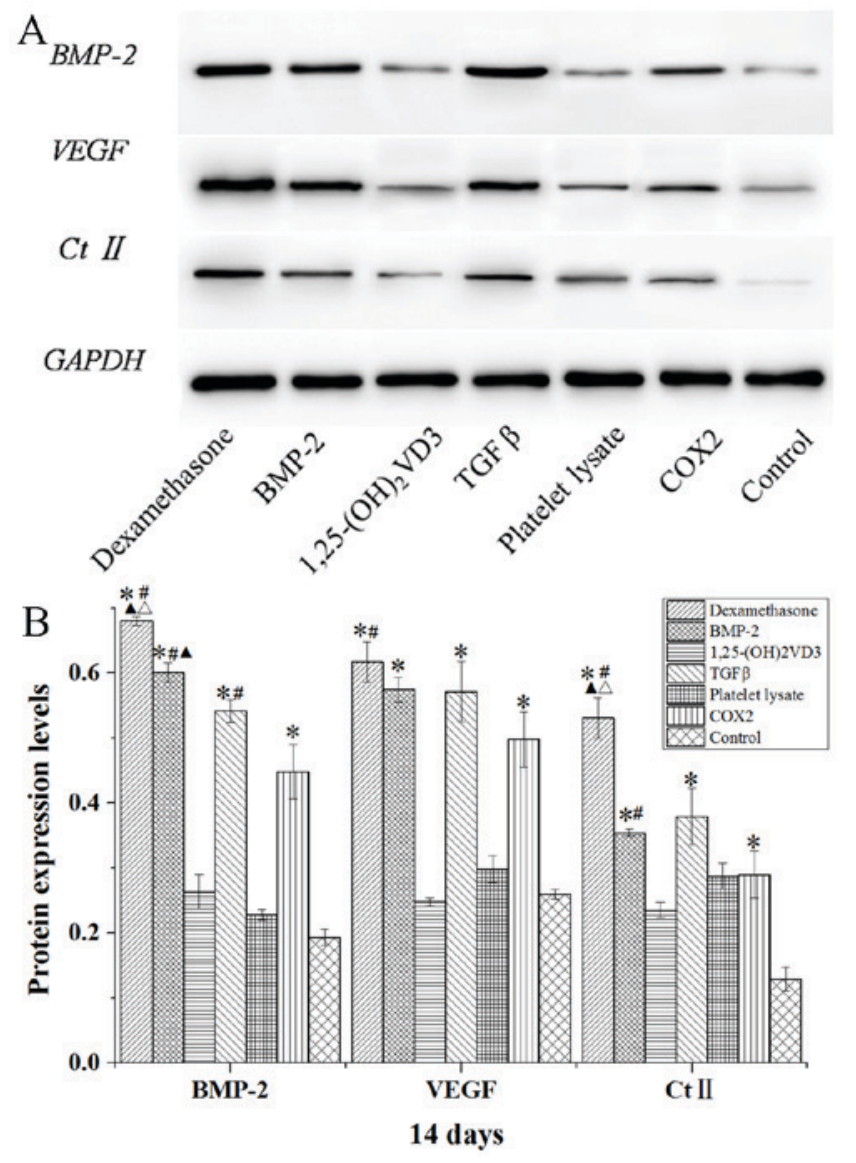

Figure 9. Western blot analysis of BMP-2, VEGF and Ct II protein expression levels in rabbit mesenchymal stem cells cultured in osteogenic media for 14 days. (A) Western blotting bands were quantified using Quantity One 5.0 and demonstrated as (B) BMP-2/GAPDH, VEGF/GAPDH and Ct II/GAPDH. Data are presented as the mean \pm standard deviation $(\mathrm{n}=3)$. ${ }^{*} \mathrm{P}<0.05$ vs. the control; ${ }^{\#} \mathrm{P}<0.05$ vs. the COX2 group; ${ }^{\Delta} \mathrm{P}<0.05$ vs. TGF $\beta$ group; ${ }^{\Delta} \mathrm{P}<0.05$ vs. BMP-2 group. BMP-2, bone morphogenetic protein 2; VEGF, vascular endothelial growth factor; $\mathrm{Ct}$ II, collagen type II; 1,25-(OH $)_{2} \mathrm{VD} 3,1$, 25-dihydroxyvitamin D3; COX2, cyclooxygenase 2 .

in the dexamethasone, BMP-2, TGF $\beta$ and COX2 groups (Figs. 5 and 6). However, compared with the control group the $\mathrm{Ct}$ I and osteocalcin levels in the 1,25-(OH)2VD3 and platelet lysate group revealed no notable difference. This suggests that dexamethasone, BMP-2, TGF $\beta$ and COX2 may have induced the activity of $\mathrm{Ct} \mathrm{I}$ and osteocalcin in MSCs.

BMP-2, VEGF and Ct II $m R N A$ and protein expression levels are increased in MSCs following culture in osteogenic induction media. Compared with the control group, rabbit MSCs cultured in osteogenic medium (dexamethasone, BMP-2, TGF $\beta$ and COX2 groups) for 7, 14 and 21 days demonstrated significantly increased mRNA expression levels of BMP-2, VEGF and Ct II $(\mathrm{P}<0.05$; Fig. 7). The expression level of BMP-2 was also significantly increased in the $1,25-(\mathrm{OH})_{2} \mathrm{VD} 3$ group compared with the level in the control group at days 7, 14 and $21(\mathrm{P}<0.05$; Fig. 7).

The protein expression levels of BMP-2, VEGF and Ct II in rabbit MSCs are demonstrated in Figs. 8-10. In the dexamethasone, BMP-2, TGF $\beta$ and COX 2 groups, the BMP-2, VEGF and $\mathrm{Ct}$ II protein expression levels were significantly higher than those in the control group in rabbit MSCs at 7, 14 and 21 days $(\mathrm{P}<0.05)$. The protein expression levels of BMP-2, VEGF and

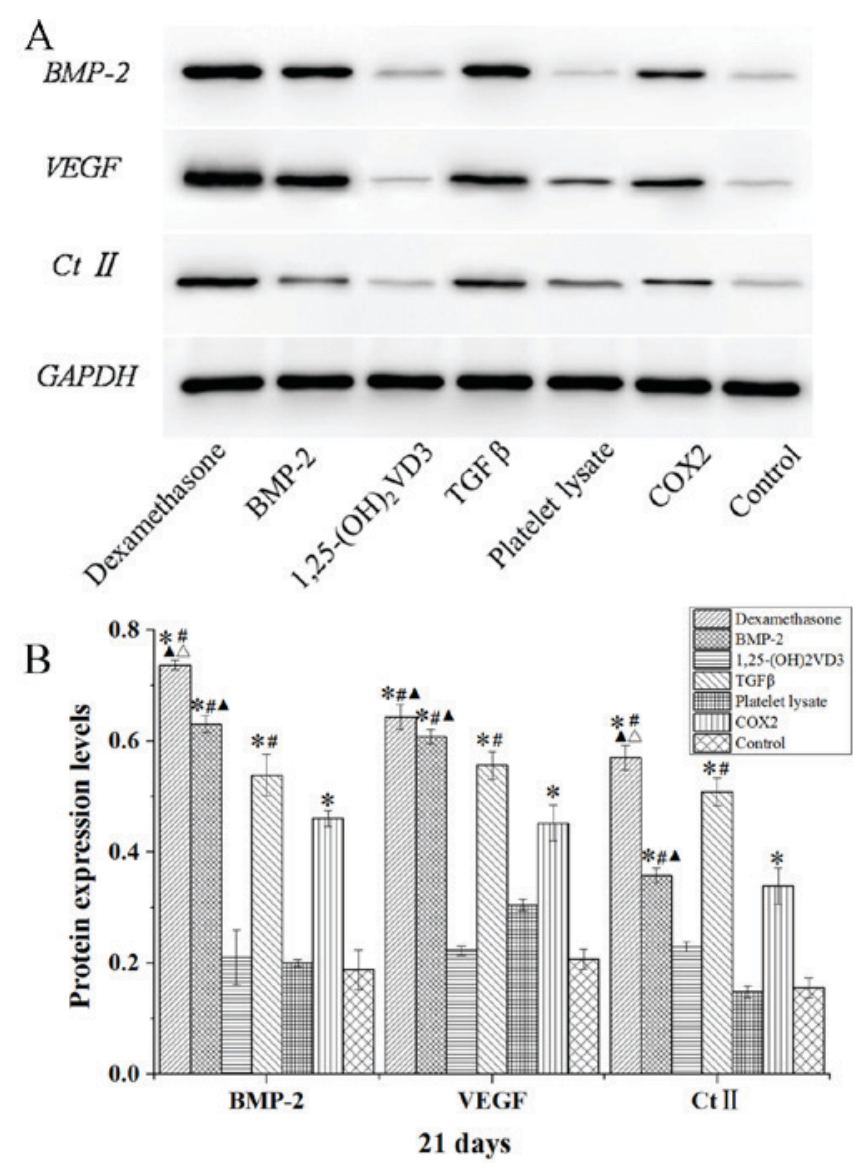

Figure 10. Western blot analysis of BMP-2, VEGF and Ct II protein expression levels in rabbit mesenchymal stem cells cultured in osteogenic media for 21 days. (A) Western blotting bands were quantified using Quantity One 5.0 and demonstrated as (B) BMP-2/GAPDH, VEGF/GAPDH and Ct II/GAPDH. Data are presented as the mean \pm standard deviation $(n=3)$. ${ }^{*} \mathrm{P}<0.05$ vs. the control; ${ }^{\#} \mathrm{P}<0.05$ vs. the COX 2 group; ${ }^{\Delta} \mathrm{P}<0.05$ vs. TGF $\beta$ group; ${ }^{\Delta} \mathrm{P}<0.05$ vs. BMP-2 group. BMP-2, bone morphogenetic protein 2; VEGF, vascular endothelial growth factor; Ct II, collagen type II; 1,25-(OH) 2 VD3, 1,25-dihydroxyvitamin D3; COX2, cyclooxygenase 2 .

Ct II were consistent with the results of their gene expression. These results indicated that dexamethasone, BMP-2, TGF $\beta$ and COX2 induced the expression of BMP-2, VEGF and $\mathrm{Ct}$ II in rabbit MSCs.

\section{Discussion}

MSCs may be induced to differentiate into multiple cell types, such as osteoblasts (23). In the present study the differentiation of rabbit MSCs was studied and markers of differentiation were analyzed. Additionally, MSCs were differentiated in different culture media, including media containing dexamethasone, BMP-2, COX2, TGF $\beta$, platelet lysate and 1,25- $(\mathrm{OH})_{2} \mathrm{VD} 3$, respectively, and its effect was analyzed by measuring ALP activity, mineralization and expression of related genes and proteins. There are various factors that affect the osteogenic differentiation of MSCs (24). In the present study, common osteogenic induction factors were selected to explore their ability to induce osteoblasts, which laid a foundation for subsequent osteogenic induction.

Several methods are used for isolation of MSCs, including negative and positive selection of cells (25), cell sorting (26) 
and applications of cytotoxic materials (27); however, these methods have varying impacts on MSC proliferation and differentiation. In the present report, a simple method was utilized for the isolation of MSCs. Cells were successfully isolated and were attached to the surface of plates. Mostly circular-shaped cells of uniform size were observed after culture for $24 \mathrm{~h}$ and, following additional days of culture, the cells demonstrated spindle-shaped morphology.

The increase of ALP activity is an important marker of MSC differentiation into osteoblasts. ALP is highly expressed at an early stage of osteogenic differentiation to promote cell maturation and calcification, which is therefore considered as an important indicator for early osteogenesis (28). Mineralized nodules are typically observed as a marker for terminal differentiation, and MSCs may be stained for mineral deposition by Alizarin Red S (29). As indicated in the present study, the expression level of ALP was markedly higher in differentiating cells that were cultured in dexamethasone, BMP-2 and TGF $\beta$ media. The present study demonstrated the positive impact of dexamethasone, BMP-2 and TGF $\beta$ on the development of mineralized nodules by detecting the calcium influx. Previous studies have revealed that dexamethasone suppressed the proliferation and accelerated the differentiation process of the MSCs (12,30). BMP-2 has emerged as a key regulator of stem cell commitment and serves an essential role in osteogenic differentiation (31). Several studies have applied BMP-2 to MSCs for the repair of cartilage tissue $(32,33)$. TGF $\beta$ is also known to promote chondrogenic differentiation (34). In the present study, immunohistochemical staining of Ct I and osteocalcin also demonstrated that the osteogenic potential of dexamethasone, BMP-2 and TGF $\beta$ was more profound than that of 1,25-(OH) $)_{2} \mathrm{VD} 3$, platelet lysate and COX2.

The expression of osteogenesis-inducing genes and proteins (BMP-2, VEGF and Ct II) in the present study were detected by RT-qPCR and western blotting. The results indicated that the mRNA and proteins expression levels of BMP-2, VEGF and Ct II were significantly increased in rabbit MSCs induced by dexamethasone, BMP-2, TGF $\beta$ and COX2. These results suggest that dexamethasone, BMP-2, TGF $\beta$ and COX 2 promote the expression of osteogenesis-inducing genes and proteins during MSC chondrogenic differentiation. The osteogenic differentiation of MSCs involves a complex process orchestrated by multiple regulatory factors and proteins. BMPs are master regulators of osteoblast differentiation (35). It has been reported that increased levels of BMP-2 promote the chondrogenic effect, as indicated by increased expression levels of $\mathrm{Ct}$ II and expression of chondrogenic markers (36). VEGF was initially recognized as an endothelial-specific growth factor, which increased vascular permeability and angiogenesis, and it is now apparent that this cytokine regulates multiple biological functions in the endochondral ossification of mandibular condylar growth, as well as long bone formation (37). A study by Peng et al (38) reported that the addition of a specific antagonist of VEGF significantly inhibited BMP-2-induced bone formation and the associated angiogenesis indicated that endogenous VEGF activity is important for bone formation. BMP-2, VEGF and Ct II are important regulators that promote osteogenic differentiation of MSCs. Accordingly, it may be inferred from the present study that dexamethasone, TGF $\beta$ and COX 2 may have the potential to increase the expression of osteogenesis-inducing genes and proteins to accelerate the osteogenic differentiation of MSCs.

In conclusion, rabbit MSCs were successfully isolated from bone marrow using a simple procedure and differentiated into osteoblast-like cells as indicated by raised ALP, $\mathrm{Ct} \mathrm{I}$ and osteocalcin activities, mineralization and increased expression of osteogenesis-inducing genes and proteins. The present study also revealed that dexamethasone, BMP-2 and TGF $\beta$ have a positive effect on MSC differentiation. These results may provide a basis for the development of sequential delivery systems for multiple growth factors in bone engineering.

\section{Acknowledgements}

The present work was supported by the Programs of Wuhan Municipal Science and Technology Bureau for Science and Technology Development (grant no. 201260523187-1) and the Project of Health and Family Planning Commission of Wuhan Municipality (grant no. WX12B13).

\section{Competing interests}

The authors declare that they have no competing interests.

\section{References}

1. Cai M, Shen R, Song L, Lu M, Wang J, Zhao S, Tang Y, Meng X, Li Z and He ZX: Bone marrow mesenchymal stem cells (BM-MSCs) improve heart function in swine myocardial infarction model through paracrine effects. Sci Rep 6: 28250 , 2016.

2. Baena RRY, Rizzo S, Graziano A and Lupi SM: Bone regeneration in implant dentistry: Role of mesenchymal stem cells. In: A Textbook of Advanced Oral and Maxillofacial Surgery 3. Motamedi MHK (ed). InTech, London, pp269-291, 2016.

3. Gerstenfeld LC, Barnes GL, Shea CM and Einhorn TA: Osteogenic differentiation is selectively promoted by morphogenetic signals from chondrocytes and synergized by a nutrient rich growth environment. Connec Tissue Res 44 (Suppl 1): S85-S91, 2003.

4. Davidson D, Blanc A, Filion D, Wang H, Plut P, Pfeffer G, Buschmann MD and Henderson JE: Fibroblast growth factor (FGF) 18 signals through FGF receptor 3 to promote chondrogenesis. J Biol Chem 280: 20509-20515, 2005.

5. Janderová L, Mcneil M, Murrell AN, Mynatt RL and Smith SR: Human mesenchymal stem cells as an in vitro model for human adipogenesis. Obes Res 11: 65-74, 2003.

6. Studeny M, Marini FC, Champlin RE, Zompetta C, Fidler IJ and Andreeff M: Bone marrow-derived mesenchymal stem cells as vehicles for interferon-beta delivery into tumors. Cancer Res 62: 3603-3608, 2002.

7. Potapova I, Plotnikov A, Lu Z, Danilo P Jr, Valiunas V, Qu J, Doronin S, Zuckerman J, Shlapakova IN, Gao J, et al: Human mesenchymal stem cells as a gene delivery system to create cardiac pacemakers. Circ Res 94: 952-959, 2004.

8. Zhang W, Zhang X, Ling J, Wei X and Jian Y: Osteo-/odontogenic differentiation of BMP2 and VEGF gene-co-transfected human stem cells from apical papilla. Mol Med Rep 13: 3747-3754, 2016.

9. Rui YF, Lui PP, Ni M, Chan LS, Lee YW and Chan KM: Mechanical loading increased BMP-2 expression which promoted osteogenic differentiation of tendon-derived stem cells. J Orthop Res 29: 390-396, 2011.

10. Yamasaki A, Itabashi M, Sakai Y, Ito H, Ishiwari Y, Nagatsuka H and Nagai N: Expression of type I, type II, and type X collagen genes during altered endochondral ossification in the femoral epiphysis of osteosclerotic (oc/oc) mice. Calcif Tissue Int 68: 53-60, 2001.

11. Atmani H, Audrain C, Mercier L, Chappard D and Basle MF: Phenotypic effects of continuous or discontinuous treatment with dexamethasone and/or calcitriol on osteoblasts differentiated from rat bone marrow stromal cells. J Cell Biochem 85: 640-650, 2002. 
12. Ahmad A and Shakoori AR: Isolation and differentiation of murine mesenchymal stem cells into osteoblasts in the presence and absence of Dexamethasone. Pak J Zool 44: 1417-1422, 2012.

13. Kim S, Kang Y, Krueger CA, Sen M, Holcomb JB, Chen D, Wenke JC and Yang Y: Sequential delivery of BMP-2 and IGF-1 using a chitosan gel with gelatin microspheres enhances early osteoblastic differentiation. Acta Biomater 8: 1768-1777, 2012.

14. Song I, Kim BS, Kim CS and Im GI: Effects of BMP-2 and vitamin D 3, on the osteogenic differentiation of adipose stem cells. Biochem Biophys Res Commun 408: 126-131, 2011.

15. Majumdar HK, Banks V, Peluso D and Morris EA: Isolation, characterization and chondrogenic potential of human bone marrow-derived stromal cells. J Cell Physiol 185: 98-106, 2000.

16. Marie PJ and Fromigué O: Osteogenic differentiation of human marrow-derived mesenchymal stem cells. Regen Med 1: 539-548, 2006.

17. Zhou Y, Wu Y, Jiang X, Zhang X, Xia L, Lin K and Xu Y: The effect of Quercetin on the osteogenesic differentiation and angiogenic factor expression of bone marrow-derived mesenchymal stem cells. PLoS One 10: e0129605, 2015.

18. Zeng Q, Li X, Beck G, Balian G and Shen FH: Growth and differentiation factor-5 (GDF-5) stimulates osteogenic differentiation and increases vascular endothelial growth factor (VEGF) levels in fat-derived stromal cells in vitro. Bone 40: 374-381, 2007.

19. Ghilzon R, Mcculloch CA and Zohar R: Stromal mesenchymal progenitor cells. Leuk Lymphoma 32: 211-221, 1999.

20. Toquet J, Rohanizadeh R, Guicheux J, Couillaud S, Passuti N, Daculsi $G$ and Heymann D: Osteogenic potential in vitro of human bone marrow cells cultured on macroporous biphasic calcium phosphate ceramic. J Biomed Mater Res 44: 98-108, 1999.

21. Society for Neuroscience. Policies on the use of animals and humans in research. Society for Neuroscience.

22. Livak KJ and Schmittgen TD: Analysis of relative gene expression data using real-time quantitative PCR and the 2(-Delta Delta C(T)) method. Methods 25: 402-408, 2001

23. Gao RT, Zhan LP, Meng C, Zhang N, Chang SM, Yao R and Li C: Homeobox B7 promotes the osteogenic differentiation potential of mesenchymal stem cells by activating RUNX2 and transcript of BSP. Int J Clin Exp Med 8: 10459-10470, 2015.

24. Hu Y, Tang XX and He HY: Gene expression during induced differentiation of bone marrow mesenchymal stem cells into osteoblasts. Genet Mol Res 12: 6527-6534, 2013.

25. Nadri S and Soleimani M: Isolation murine mesenchymal stem cells by positive selection. In Vitro Cell Dev Biol Anim 43 276-82, 2007.

26. Van Vlasselaer P, Falla N, Snoeck H and Mathieu E: Characterization and purification of osteogenic cells from murine bone marrow by two-color cell sorting using anti-Sca-1 monoclonal antibody and wheat germ agglutinin. Blood 84 753-763, 1994.

27. Modderman WE, Vrijheid-Lammers T, Löwik CW and Nijweide PJ: Removal of hematopoietic cells and macrophages from mouse bone marrow cultures: Isolation of fibroblastlike stromal cells. Exp Hematol 22: 194-201, 1994.
28. Hu H, Chen M, Dai G, Du G, Wang X, He J, Zhao Y, Han D, Cao Y, Zheng Y and Ding D: An Inhibitory Role of Osthole in Rat MSCs Osteogenic Differentiation and Proliferation via Wnt $/ \beta$-Catenin and Erk1/2-MAPK Pathways. Cell Physiol Biochem 38: 2375-2388, 2016.

29. Yun HM, Park KR, Quang TH, Oh H, Hong JT, Kim YC and Kim EC: 2,4,5-Trimethoxyldalbergiquinol promotes osteoblastic differentiation and mineralization via the BMP and Wnt/3-catenin pathway. Cell Death Dis 6: e1819, 2015

30. Walsh S, Jordan GR, Jefferiss C, Stewart K and Beresford JN: High concentrations of dexamethasone suppress the proliferation but not the differentiation or further maturation of human osteoblast precursors in vitro: Relevance to glucocorticoid-induced osteoporosis. Rheumatology (Oxford) 40: 74-83, 2001.

31. Rui YF, Lin DU, Wang Y, Wang Y, Lui PP, Tang TT, Chan KM and Dai KR: Bone morphogenetic protein 2 promotes transforming growth factor $\beta 3$-induced chondrogenesis of human osteoarthritic synovium-derived stem cells. Chin Med J (Engl) 123: 3040-3048, 2010.

32. Sekiya I, Larson BL, Vuoristo JT, Reger RL and Prockop DJ: Comparison of effect of BMP-2, -4 , and -6 on in vitro cartilage formation of human adult stem cells from bone marrow stroma. Cell Tissue Res 320: 269-276, 2005.

33. Kurth T, Hedbom E, Shintani N, Sugimoto M, Chen FH, Haspl M, Martinovic S and Hunziker EB: Chondrogenic potential of human synovial mesenchymal stem cells in alginate. Osteoarthritis Cartilage 15: 1178-1189, 2007.

34. Barry F, Boynton RE, Liu B and Murphy JM: Chondrogenic differentiation of mesenchymal stem cells from bone marrow: Differentiation-dependent gene expression of matrix components. Exp Cell Res 268: 189-200, 2001.

35. Lo YC, Chang YH, Wei BL, Huang YL and Chiou WF: Betulinic acid stimulates the differentiation and mineralization of osteoblastic MC3T3-E1 cells: Involvement of BMP/Runx2 and $\beta$-catenin signals. J Agric Food Chem 58: 6643-6649, 2010.

36. Shirasawa S, Sekiya I, Sakaguchi Y, Yagishita K, Ichinose S and Muneta T: In vitro chondrogenesis of human synovium-derived mesenchymal stem cells: Optimal condition and comparison with bone marrow-derived cells. J Cell Biochem 97: 84-97, 2006.

37. Dai J and Rabie AB: VEGF: An essential mediator of both angiogenesis and endochondral ossification. J Dent Res 86: 937-950, 2007.

38. Peng H, Usas A, Olshanski A, Ho AM, Gearhart B, Cooper GM and Huard J: VEGF improves, whereas sFlt1 inhibits, BMP2-induced bone formation and bone healing through modulation of angiogenesis. J Bone Miner Res 20: 2017-2027, 2005.

This work is licensed under a Creative Commons Attribution-NonCommercial-NoDerivatives 4.0 International (CC BY-NC-ND 4.0) License. 